\title{
ВИДОВОЙ СОСТАВ НАЗЕМНЫХ ТИХОХОДОК (TARDIGRADA) ОКРЕСТНОСТЕЙ ЧУПИНСКОЙ ГУБЫ (ЛОУХСКИЙ РАЙОН, РЕСПУБЛИКА КАРЕЛИЯ)
}

Банникова Мария Александровна
Аспирант Бисерова Наталья Михайловна д.б.н., вед. науч. сотр. Московский государственный университет имени М. В. Ломоносова Заботин Ярослав Игоревич к. б. н., доцент Казанский (Приволжский) федеральный университет

Аннотация: Для описания фауны наземных тихоходок Карелии исследовали наземные пробы мха, собранные в период с 2017 по 2020 гг. В пробах были обнаружены как взрослые особи Tardigrada, так и их яйца. Кроме того, в некоторых случаях были извлечены из яиц и исследованы эмбрионы тихоходок. Всего было идентифицировано 8 видов тихоходок.

Ключевые слова: Тихоходки, видовой состав, Чупинская губа, Карелия, Heterotardigrada, Eutardigrada, Echiniscoidea, Apochela, Parachela.

\section{SPECIES COMPOSITION OF TERRESTRIAL TARDIGRADES (TARDIGRADA) IN THE SURROUNDINGS OF CHUPA BAY (LOUKHSKY DISTRICT, REPUBLIC OF KARELIA)}

\section{Bannikova Maria Alexandrovna Biserova Natalia Mihailovna Zabotin Yaroslav Igorevich}

\begin{abstract}
To describe the fauna of Karelian land tardigrades, ground moss samples collected in the period from 2017 to 2020 were studied. Both adult Tardigrada individuals and their eggs were found in the samples. In addition, in some cases, slow-moving embryos were extracted from eggs and examined. A total of 8 species of tardigrades have been identified.
\end{abstract}

Key words: Tardigrades, species composition, Chupa Bay, Karelia, Heterotardigrada, Eutardigrada, Echiniscoidea, Apochela, Parachela. 
Tardigrada - группа микроскопических широко распространенных беспозвоночных животных. В настоящее время они очень популярны в научном мире, их часто используют в качестве модельных организмов для исследований в самых различных областях: астробиологии, физиологии, эволюционной экологии и многих других.

Несмотря на значительный научный интерес к этой группе беспозвоночных, объем данных о видовом разнообразии мировой фауны Tardigrada остается недостаточным [1, с. 4$]$.

На сегодняшний день фауна тихоходок республики Карелия в целом остается малоизученной. Проведенные в данном регионе исследования в основном посвящены водным тихоходкам, пресноводным (Туманов, 1997) [1] и морским (Мокиевский и др., 2015; Петелина, Чесунов, 1983; Veliushova, Tchesunov, 2016) [2, 3, 4] видам. Имеющиеся данные по видовому составу Tardigrada наземных биотопов в значительной мере ограничены (Чесунов и др., 2008; Бисеров, Туманов, 1993) [5, 6].

Чупинская губа расположена в Лоухском районе, самом северном районе республики Карелия и является самым южным фьордом БаренцевоБеломорского региона [7, с. 43, 44]. Она представляет собой залив, испещренный узкими длинными бухтами. Со стороны берега к ней примыкает ряд поселков, а в месте выхода в Кандалакшский залив находится множество небольших островов и извилистых мысов.

\section{Материалы и методы}

Наземные пробы тихоходок были собраны в июне-июле в период с 2017 по 2020 гг. в следующих районах (в скобках указаны года сбора): о. Средний, территория Беломорской биологической станции (ББС) КФУ $(2017,2018)$; о. Средний, Юшкова губа (2017, 2018); о. Средний, оз. Большое (2020); губа Осечково (2020); с. Кереть (2017, 2018); мыс Картеш (2017); о. Медянка (2017); о. Луда-Черемшиха (2017); о. Сидоров (2020).

Пробы высушивали при комнатной температуре для предотвращения загнивания. Перед просмотром пробы замачивали в водопроводной воде в течение 0,5-2 часов. Из получившегося осадка тихоходки и их яйца извлекались с помощью капиллярной пипетки. Эмбрионы из яиц извлекали с помощью препаровальных игл.

\section{Световая микроскопия}

Временные препараты тихоходок и их яиц просматривали и фотографировали при помощи светового микроскопа Axio Imager. При 418 
необходимости некоторые детали строения были сняты послойно в различных плоскостях. Затем снимки были совмещены и отредактированы в программе Helicon Focus. Посторонние частицы вокруг исследуемых объектов были удалены с помощью программы Photoshop.

Сканирующая электронная микроскопия (СЭМ)

1) Пробы, собранные в 2017 г. Тихоходки были зафиксированы целиком в 1\% глутаровом альдегиде на 0,1 М фосфатном буфере. Пробоподготовка включала промывку в фосфатном буфере и дегидратацию спиртовым рядом от $30 \%$ до абсолютного. Дегидратированные образцы высушивали на воздухе и монтировали на покровное стекло, после чего покрывали золото-палладиевым напылением в вакуумном напылителе «Quorum», затем исследовали и фотографировали с помощью СЭМ «Merlin Zeiss» в Центре аналитической микроскопии Казанского Федерального Университета (КФУ).

2) Пробы, собранные в 2018-2019 гг. Тихоходки были зафиксированы в 70\% спирте, после чего высушены на воздухе на покровных стеклах. Образцы покрывали золото-палладиевым напылением в вакуумном напылителе «Quorum», затем исследовали и фотографировались с помощью СЭМ «Merlin Zeiss» в Центре аналитической микроскопии КФУ.

3) Пробы, собранные в 2020 г. Тихоходки были зафиксированы в 70\% спирте, после чего высушены на воздухе на покровных стеклах. Образцы покрывали платино-палладиевым напылением и исследовали при помощи СЭМ JSM-6380LA в межкафедральной лаборатории электронной микроскопии (МЛЭМ) Биологического факультета МГУ.

Для определения видов использовали монографию Ramazzotti, Maucci, 1983 [8]. Систематика видов приведена по Degma et al., 2021 [9].

В пробах, собранных на губе Осечково, на мысе Картеш и о. Сидоров, тихоходок обнаружено не было.

\section{Результаты}

Класс Heterotardigrada Marcus, 1927

Отряд Echiniscoidea Richters, 1926

Семейство Echiniscidae Thulin, 1928

Echiniscus merokensis merokensis Richters, 1904

Деревня Кереть, 2018 г. пробы мха с камня. Было обнаружено 6 особей данного вида. Все экземпляры имели типичный набор латеральные отростков филаменты A, C, D, E. Дорсальные отростки $\mathrm{C}^{\mathrm{d}}$, у всех особей также были 419 
представлены филаментами. Дорсальные отростки $\mathrm{D}^{\mathrm{d}}$ присутствовали у 4 особей в виде небольшого треугольного шипа, и у 2 особей полностью отсутствовали (рис. 1).

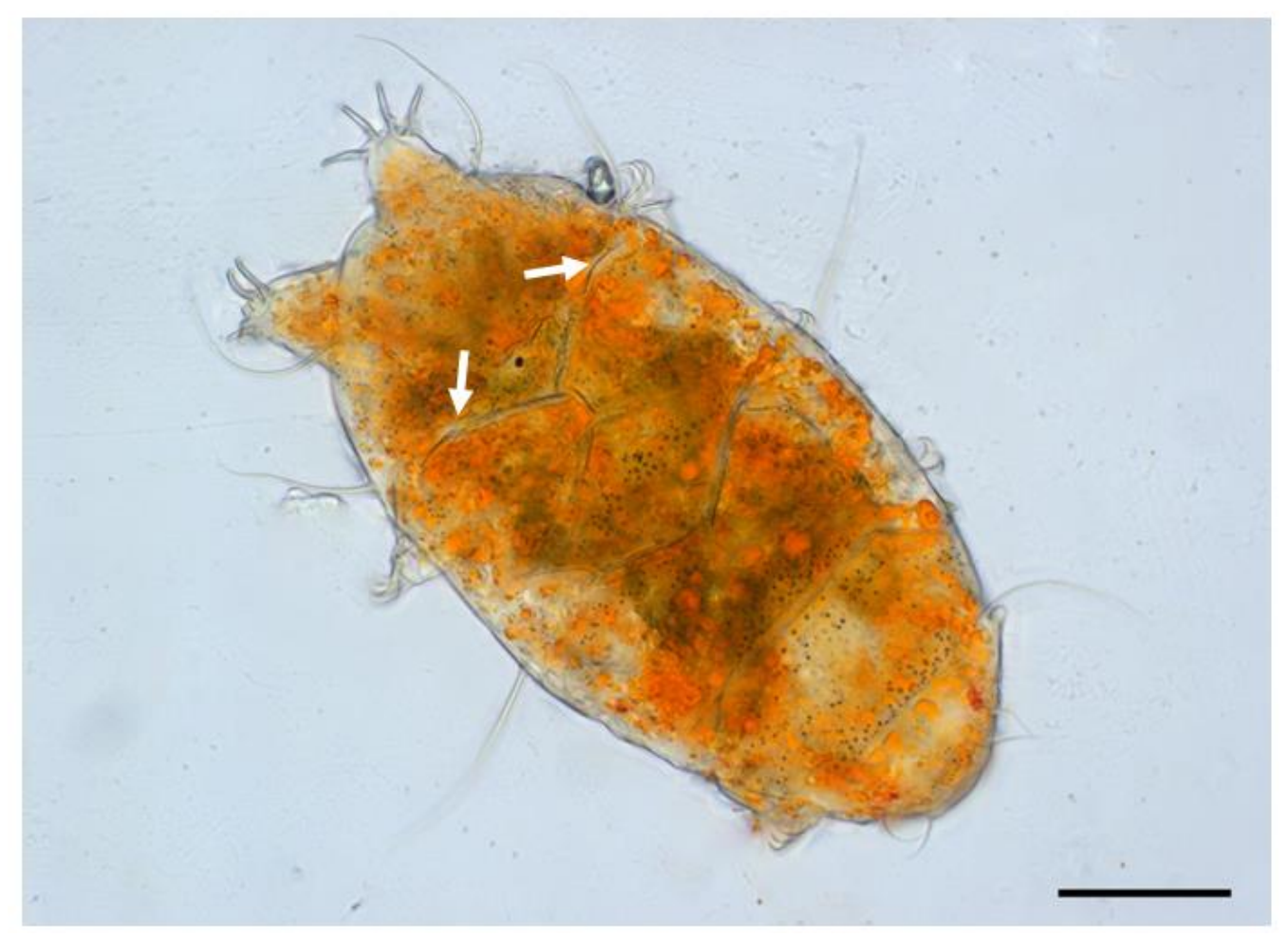

Рис. 1. Общий вид E. merokensis merokensis. Стрелки указывают на местоположение отсутствующих шипов $\mathrm{D}^{\mathrm{d}}$. Масштаб 50 мкм.

Класс Eutardigrada Richters, 1926

Отряд Apochela Schuster, Nelson, Grigarick \& Christenberry, 1980

Семейство Milnesiidae Ramazzotti, 1962

Milnesium tardigradum tardigradum (Doyere, 1840)

Был обнаружен в пробах 2017 г. на о. Средний (Юшкова губа: 4 особи и 1 экзувий; территория ББС КФУ: 1 экзувий) и в с. Кереть. 2 особи.

Отряд Parachela Schuster, Nelson, Grigarick \& Christenberry, 1980

Семейство Hypsibiidae Pilato, 1969

Подсемейство Itaquasconinae Bartos in Rudescu, 1964

Astatumen trinacriae (Arcidiacono, 1962)

Пробы из с. Кереть 2017 г. 2 особи.

Mesocrista spitzbergensis (Richters, 1903)

Было обнаружено 2 особи в пробах с территории ББС КФУ 2019 г. и 1 особь в с. Кереть 2018 г.

Надсемейство Macrobiotoidea Thulin, 1928 in Marley et al. 2011

Семейство Macrobiotidae Thulin, 1928 
Macrobiotus hufelandi Schultze, 1834

Вид был обнаружен во всех пробах, где присутствовали тихоходки. Также было обнаружено 6 яиц в пробах из с. Кереть (2018 г) и 3 яйца с Юшковой губы (о. Средний) (2018 г). Тонкое строение яиц характеризуется наличием выступов с зубчатым апикальным диском. Количество зубчиков обычно варьирует от 10 до 13 (рис. 2). Поверхность выступа непосредственно под апикальным диском образует несколько хорошо заметных ребер, базальная часть выступа обычно гладкая (рис. 2). На поверхности между выступами хорошо различимы два слоя. Верхний имеет ячеистую структуру, причем размер ячеек вокруг выступов несколько больше, чем между ними. В просветах ячеек хорошо просматривается нижележащий гладкий слой.

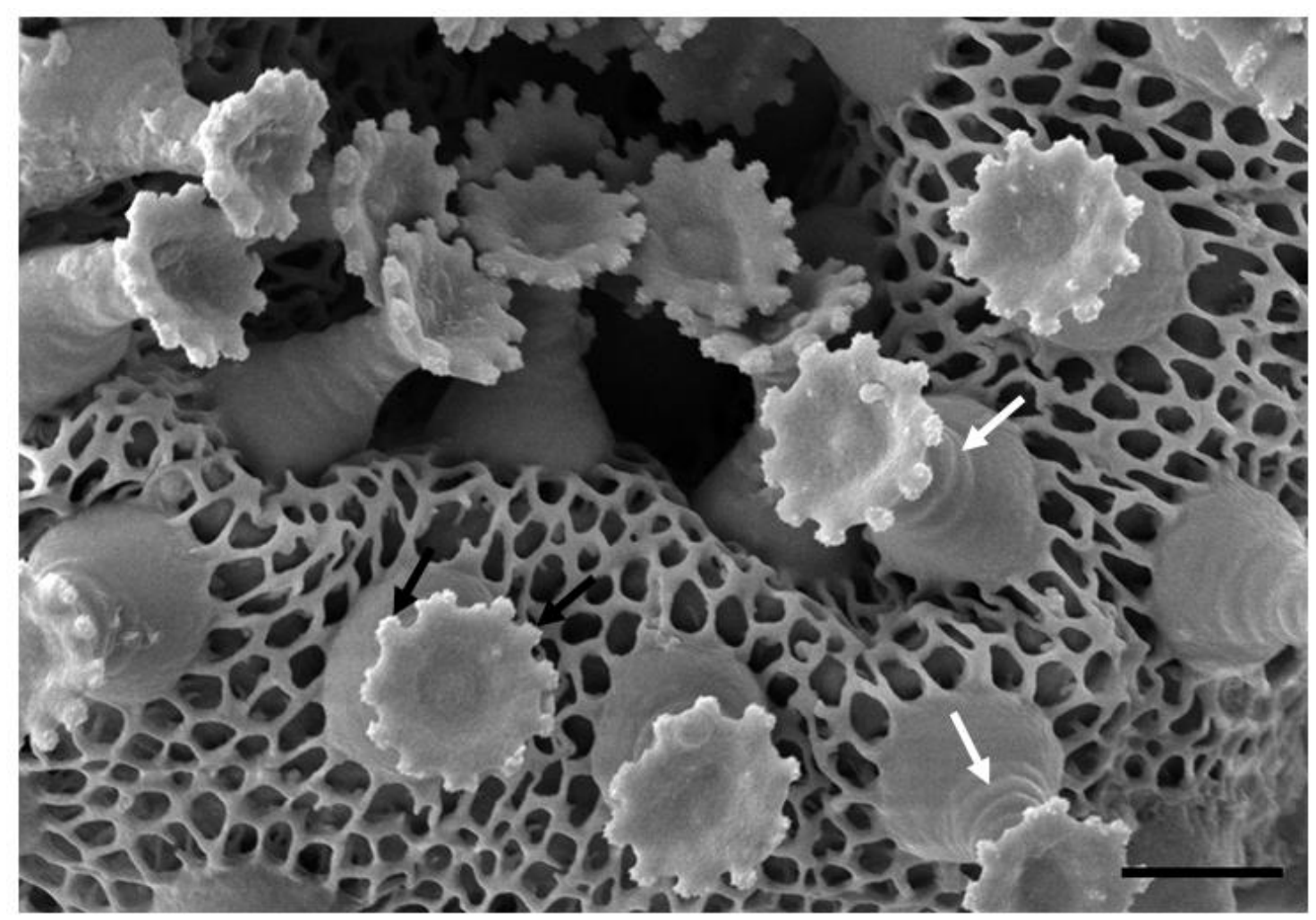

Рис. 2. Выросты хориона яйца M. Hufelandi, СЭМ. Черными стрелками показаны зубчики апикального диска, белыми - ребристая поверхность выступа. Масштаб 3 мкм.

Minibiotus intermedius (Plate, 1888)

Было обнаружено 3 особи в пробах из с. Кереть (2018, 2019 гг), и 2 с о. Средний (территория ББС КФУ: 1 особь; Юшкова губа: 1 особь)

Группа видов Paramacrobiotus richtersi (Murray, 1911) 
Взрослые особи были обнаружены на территории ББС КФУ. Кроме того было обнаружено 21 яйцо в пробах из с. Кереть $(2018,2019$ гг) и 6 яиц с о. Средний (2 яйца с территории ББС КФУ, 4 яйца с Юшковой губы) $(2018,2019$ гг).

Семейство Murrayidae Guidetti, Rebecchi \& Bertolani, 2000

Dactylobiotus dispar (Murray, 1907)

Пробы мха с берега озера Большое (о. Средний). В пробе было обнаружено большое количество яиц (ок. 20) и всего 2 взрослые особи. Также были исследованы 4 эмбриона, извлеченные из яиц. Яйца этого вида характеризуются наличием небольших (ок. 5 мкм) конических выступов, чаще всего с острой или раздвоенной вершиной (иногда вершина разделяется на три и более ветвей) (рис. 3). У эмбрионов, выделенных из яиц, наблюдали характерные для данного вида строение рото-глоточного аппарата и коготков, от взрослых особей отличались лишь более мелкими размерами (ок. 200 мкм) (рис. 4, 5).

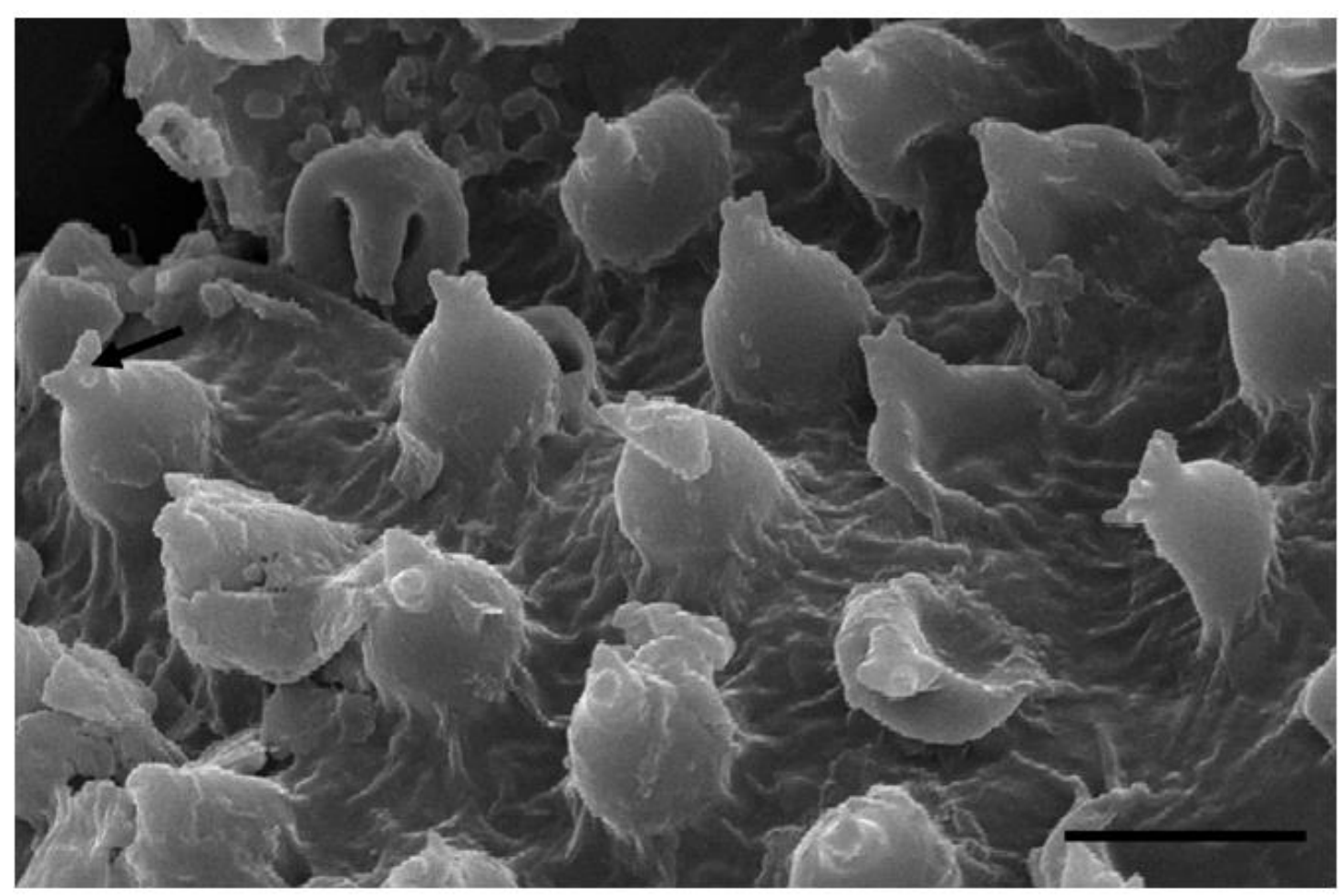

Рис. 3. Выросты хориона яйца D. dispar, СЭМ. Стрелкой отмечен выступ с тройной вершиной. Масштаб 5 мкм. 


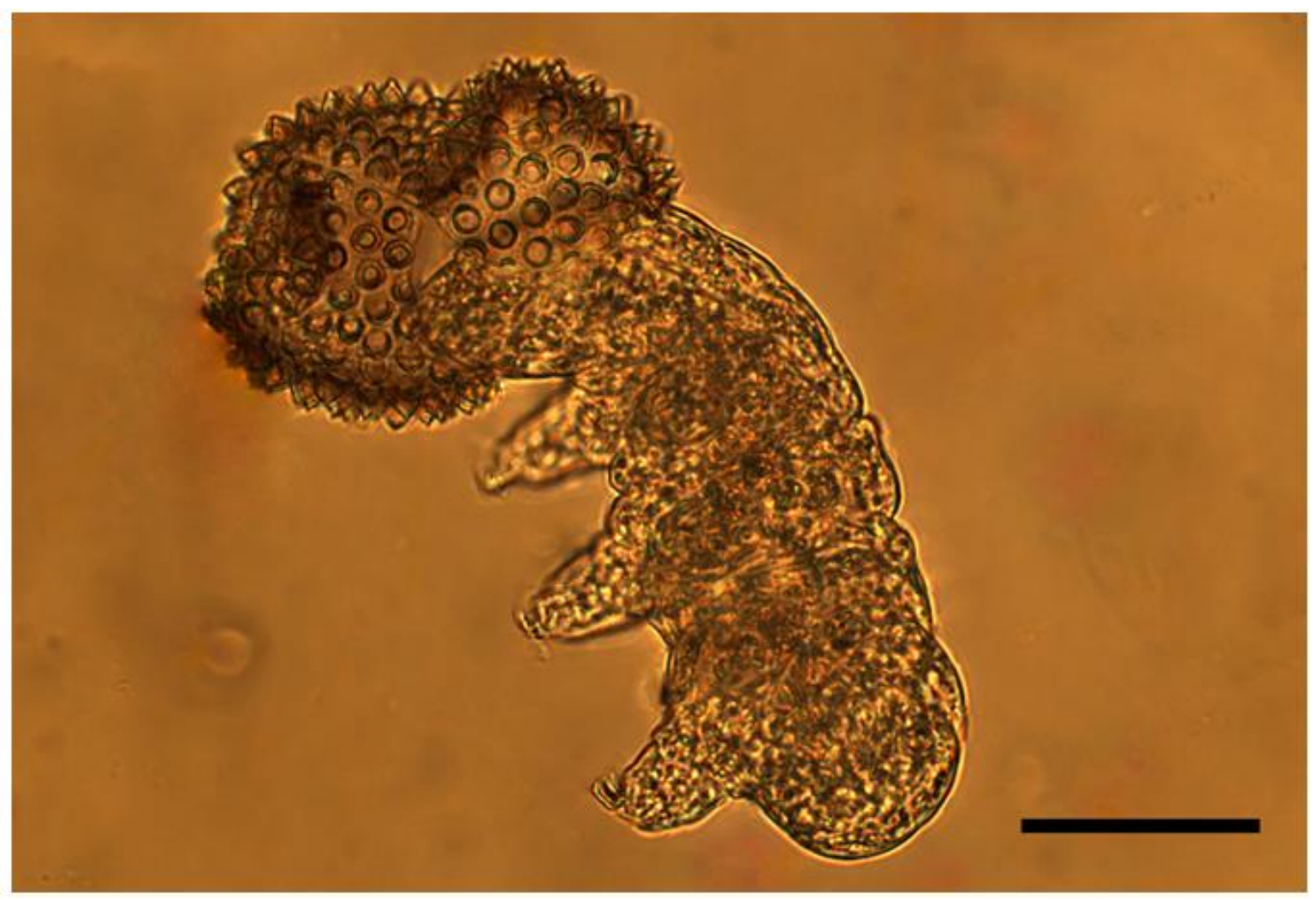

Рис. 4. Яйцо D. dispar и извлеченный из него эмбрион. Масштаб 50 мкм.

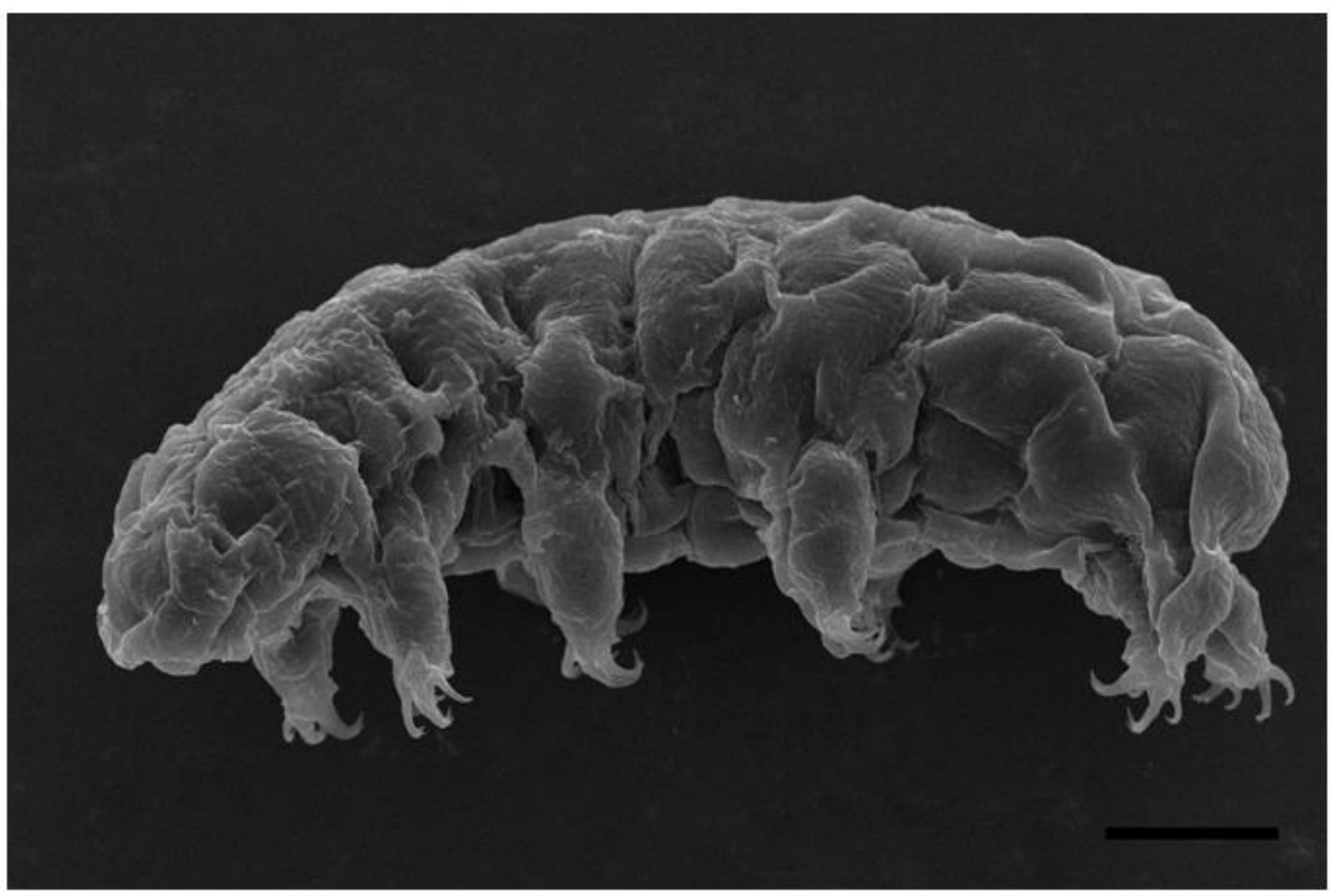

Рис. 5. Эмбрион D. dispar, СЭМ. Масштаб 20 мкм. 


\section{Обсуждение результатов}

\section{Echiniscus merokensis merokensis}

Echiniscus merokensis merokensis является широко распространенным видом. Он встречается в странах Европы, Азии, Африки и Америки [13, с. 269]. В России был обнаружен на Таймырском полуострове [11, с. 217], на Кавказе $[12$, с. 750$]$, в Хибинах, в республике Коми и Ненецком автономном округе. Также имеются данные об обитании Echiniscus merokensis merokensis на территории Карелии [13, с. 269].

Для данного вида характерна значительная морфологическая изменчивость, особенно это касается дорсальных отростков [10, с. 13], [8, с. 412]. Отростки $\mathrm{C}^{\mathrm{d}}$ могут быть представлены филаментами, короткими шипами либо совсем отсутствовать. То же самое происходит и с отростками $\mathrm{D}^{\mathrm{d}}$, которые в норме имеют вид короткого треугольного зубца, однако могут достигать значительной длины, сопоставимой с выростом $\mathrm{C}^{\mathrm{d}}$, или совсем отсутствовать. В редких случаях может наблюдаться асимметрия между правым и левым дорсальными шипами [8, с. 413].

\section{Milnesium tardigradum}

Эврибионтный, космополитический вид. Чаще встречается в наземных биотопах [14, с. 28]. В Карелии известен на территории ББС МГУ [5, с. 329].

Astatumen trinacriae

Широко распространенный голарктический вид. В России встречается на Кавказе, в Карелии, Архангельске, Мурманске, Вологде, Ульяновске, Смоленске, Москве [13, с. 315] и Татарстане [14, с. 31].

Mesocrista spitzbergense

Обитает в странах Европы, в Японии, Северной Америке и Арктике. В России распространен в северных районах [13, с. 322], в том числе и в Республике Карелия [1, с. 16].

\section{Macrobiotus hufelandi}

Самый распространенный вид Tardigrada, встречается повсеместно [15, с. 61]. Имеются литературные данные об обитании данного вида в озерах республики Карелия [1, с. 14], а также на территории ББС МГУ [5, с. 329].

Minibiotus intermedius

Широко распространенный космополитический вид. Имеются данные об обитании данного вида на территории ББС МГУ [5, с. 329].

\section{Paramacrobiotus richtersi}

Группа включает следующие виды:

1. Paramacrobiotus fairbanksi Schill, Förster, Dandekar \& Wolf, 2010 424 
2. Paramacrobiotus kenianus Schill, Förster, Dandekar \& Wolf, 2010

3. Paramacrobiotus palaui Schill, Förster, Dandekar \& Wolf, 2010

4. Paramacrobiotus richtersi (Murray, 1911)

Виды, принадлежащие к этой группе, не могут быть идентифицированы по внешним признакам, так как виды P. fairbanksi, P. kenianus, P.palaui были диагностированы лишь на основе генетических данных, и никаких морфологических отличий от P. richtersi обнаружено не было [9, с. 49].

Данная группа является широко распространенной. Чаще всего встречается в наземных биоценозах [15, с. 61]. Известно, что на территории России встречается практически повсеместно кроме степных и полупустынных климатических зон [13, с. 291], однако конкретные литературные данные об обитании в Республике Карелия найдены не были. Возможно, это первая находка данной группы видов для Республики Карелия.

Dactylobiotus dispar

Одна из самых обычных пресноводных тихоходок [15, с. 61]. Обитает в странах Европы, Африки, Азии, в Австралии, Арктике, Новой Зеландии, Северной и Южной Америке, а также в Атлантике[13, с. 295]. В России обитает на Таймырском полуострове [11, с. 231], Земле Франца-Иосифа, в Ненецком автономном округе, Ярославле [13, с. 295], Татарстане [14, с. 28], Ленинградской области [1, с. 14], в Карелии обнаружен в Ладожском озере $[13$, c. 295].

\section{Список литературы}

1. Туманов, Д. В. Пресноводные тихоходки (Tardigrada) СевероЗапада России: автореферат диссертации на соискание степени кандидата биологических наук. - Спб - 1997. - 24 с.

2. Мокиевский В. О., Колбасова Г. Д., Пятаева С. В., Цетлин А. Б. Мейобентос. Методическое пособие по полевой практике. - М.: Товарищество научных изданий КМК, - 2015. - 199 с.

3. Петелина О.Ю., Чесунов А.В. Новый представитель фауны Белого моря - тихоходка Hypsibius apelloefi (Tardigrada) // Зоологический журнал. 1983. - № 1. - C. 117-120.

4. Veliushova A.I., Tchesunov A.V. Marine Tardigrada of the White Sea, North Russia // Lampadariou N., Sevastou K., Eleftheriou A. (eds.) $16^{\text {th }}$ International Meiofauna Conference, Aquila Atlantis Hotel, 3-8 July 2016, Draft book of abstracts. - 2016. - C. 99.

5. Чесунов А. В., Калякина Н. М., Бубнова Е. Н. Каталог биоты 425 
Беломорской биологической станции МГУ. - М.: Товарищество научных изданий КМК, - 2008. - 384 с.

6. Бисеров В.И., Туманов Д.В. Ramazzottius valaamis sp.n. - новый вид тихоходок (Tardigrada, Нypsibiidae) с островов Валаамского архипелага (Карелия, Россия) //Зоологический журнал. - 1993. - № 11. - С. 35-39.

7. Антошко Е.А., Денисова Т.С., Красножон В.Г.]. Антошко, Е. А. Денисова, Т. С. Красножон, В. Г. Живем и работаем в Карелии информационные материалы по вопросам социально-культурной адаптации мигрантов. - Петрозаводск: Министерство, - 2007. - 98 с.

8. Ramazzotti, G., Maucci W. The Phylum Tardigrada. - Abilene: McMurry University, $-1983 .-1014$ p.

9. Degma P., Bertolani R., Guidetti R. Actual checklist of Tardigrada species (2009-2021, 40th Edition: 19-07-2021). - 2021. - 62 p.

10. Guil N. New records and within-species variability of Iberian tardigrades (Tardigrada), with comments on the species from the Echiniscus blumi-canadensis series // Zootaxa. - 2008. - № 1757. - C. 1-30.

11. Biserov V. I. Tardigrades of the Taimyr peninsula with descriptions of two new species // Zoological Journal of the Linnean Society. - 1996. - № 116. C. 215-237.

12. Бисеров, В. И. Наземные тихоходки Северного Кавказа. Сообщение 1. Heterotardigrada // Зоологический журнал. - 1986. - № 5. C. 747-756.

13. McInnes S. J. Zoogeographic distribution of terrestrial / freshwater tardigrades from current literature // Journal of Natural History. - 1994. - № 28. C. 257-352.

14. Дудичев, А. Л., Бисеров, В. И., Голубев, А. И. Тихоходки Татарстана: Методическое пособие по сбору и определению. - Казань: Унипресс, - 1999. - 37 с.

15. Бисеров, В.И. Определительная таблица пресноводных тихоходок СССР // Зоологический журнал. - 1989. - № 6. - С. 56-65.

(C) М.А. Банникова, Н.М. Бисерова, Я.И. Заботин, 2022 